STUDI

FRANCESI

\section{Studi Francesi}

Rivista quadrimestrale fondata da Franco Simone

169 (LVII | I) | 2013

LA RÉVOLUTION SUR SCÈNE a cura di Pierre Frantz, Paola Perazzolo, Franco Piva

\title{
Marc D. Schachter, Voluntary Servitude and the Erotics of Friendship. From Classical Antiquity to Early Modern France
}

\section{Sabine Lardon}

\section{CpenEdition}

\section{Journals}

Édition électronique

URL : http://journals.openedition.org/studifrancesi/3366

DOI : $10.4000 /$ studifrancesi.3366

ISSN : 2421-5856

Éditeur

Rosenberg \& Sellier

Édition imprimée

Date de publication : 1 avril 2013

Pagination : 159

ISSN : 0039-2944

Référence électronique

Sabine Lardon, «Marc D. Schachter, Voluntary Servitude and the Erotics of Friendship. From Classical Antiquity to Early Modern France », Studi Francesi [En ligne], 169 (LVII | I) | 2013, mis en ligne le 30

novembre 2015, consulté le 18 septembre 2020. URL : http://journals.openedition.org/studifrancesi/ 3366 ; DOI : https://doi.org/10.4000/studifrancesi.3366

Ce document a été généré automatiquement le 18 septembre 2020.

\section{(c) $(1) \Theta$}

Studi Francesi è distribuita con Licenza Creative Commons Attribuzione - Non commerciale - Non opere derivate 4.0 Internazionale. 


\title{
Marc D. Schachter, Voluntary Servitude and the Erotics of Friendship. From Classical Antiquity to Early Modern France
}

\author{
Sabine Lardon
}

\section{RÉFÉRENCE}

MARC D. SCHACHTER, Voluntary Servitude and the Erotics of Friendship. From Classical Antiquity to Early Modern France, Hampshire / Burlington, Ashgate, 2008, pp. 227.

1 Le chapitre 1 («Voluntary Servitude, Governmentality and the Care of the Self») part du rapport entre la «servitude volontaire» de La Boétie et le Banquet de Platon auquel l'expression est empruntée (discours de Pausanias), pour être employée dans une réflexion politique. Les chapitres 2 à 3 vont suivre en trois temps ce concept à travers la pensée de La Boétie tout d'abord («Critique and Governmentality in La Boétie's Mesnagerie de Xenophon and Servitude volontaire»), de Montaigne ensuite («Montaigne's «Voluntary Liberty» and the Politics of Friendship») et de Marie de Gournay enfin («Friendly Usurpations: Gournay and Montaigne»). Tandis que La Boétie renouvelle le discours politique traditionnel, exerçant une véritable «critique» au sens où Foucault l'entend, Montaigne exerce ce même esprit de liberté en déplaçant la «servitude volontaire» dans un contexte apolitique. Nés de la perte de l'ami, les Essais sont le lieu d'une conversation prolongée et d'un deuil continu, jusqu'à devenir consubstantiels à La Boétie, auquel Montaigne a toujours fait une place, comme le montre «l'erreur» de numérotation du chapitre 29 , toujours maintenue du vivant de l'auteur jusque dans l'exemplaire de Bordeaux. Cette place, Marie de Gournay cherchera à l'usurper en consacrant quarante ans de sa vie à l'édition et à la promotion de l'œuvre de Montaigne, comme Montaigne l'avait fait avant elle pour La Boétie, exerçant à son tour une servitude volontaire en renonçant aux obligations de femme mariée pour mieux se 
consacrer à son amitié envers Montaigne, ainsi que le montrent son travail d'éditrice et son roman, Le Promenoir de M. de Montaigne. Le dernier chapitre («The Erotics of Friendship and the Politics of Love») tente d'éclairer les positions de Montaigne sur l'amitié virile (dont les femmes sont exclues), les relations hommes-femmes et le mariage, pour voir comment la servitude volontaire devient chez lui l'exercice d'une «liberté volontaire» qui, par-delà sa dimension fondamentalement éthique, n'en a pas moins des répercussions politiques. Le concept de «servitude volontaire» pensé en termes de «liberté volontaire» permet d'explorer la pensée de La Boétie, de Montaigne et de Marie de Gournay sur les différentes nuances des relations humaines, tant politiques que privées (amitié, homosexualité, désir, mariage...). D'un bout à l'autre de l'ouvrage, la réflexion est toujours guidée par un fil directeur tiré entre les penseurs de l'antiquité (Platon, et le discours de Pausanias dans le Banquet, évoquant entre autres les relations d'Aristogiton et Harmodius; Plutarque, Erotikos) et les penseurs modernes, au premier rang desquels Michel Foucault et Jacques Derrida. S'il s'inscrit donc pleinement dans les études montaigniennes, l'ouvrage, complété par une bibliographie et un index des noms propres et des notions (elles-mêmes subdivisées), explore également les liens entre éthique et politique, amitié virile et homosexualité, tout en montrant comment des ouvrages anciens peuvent être lus au moyen des concepts de la critique moderne. 